\title{
Ensayando una reflexión sobre el ensayo
}

\author{
Fernando IBARRA CHÁvEZ \\ Universidad Nacional Autónoma de México
}

\begin{abstract}
Actualmente, en el contexto literario, el término 'ensayo' goza de una tradición añeja y su significado se ha estandarizado en todo el mundo. Sin embargo, como palabra, 'ensayo' sufrió una serie de procesos de asimilación que no se resolvieron hasta el siglo XX. El presente trabajo da cuenta de algunos ejemplos panorámicos que pueden ilustrar con claridad la oscilación semántica del término desde su uso literario por Montaigne hasta los estudios teóricos más recientes, con especial atención en la tradición hispanoamericana.

PAlabRas ClaVE: ensayo, Montaigne, historia, Hispanoamérica, género.

In the literary context, the term 'essay' has a long-standing tradition, and its meaning has been standardized worldwide. However, as a word, 'essay' passed through some processes of assimilation that were not resolved until the twentieth century. This paper offers a panoramic view of the semantic adaptations of the term from its literary use by Montaigne to the most recent theoretical studies, with a focus on the Hispanic tradition.
\end{abstract}

KEYwORDS: essay, Montaigne, history, Hispanic, genre.

Entender la palabra ‘ensayo' desde sus orígenes etimológicos no resulta tan operativo como identificar el momento en que se comenzó a utilizar en el contexto literario, en dónde y bajo cuál circunstancia. Es claro que la etimología no siempre ayuda a comprender el razonamiento que dio lugar a un término porque, en el caso de neologismos, se parte generalmente de lexemas "puros" o de palabras que han modificado su significado a lo largo del tiempo y no siempre como resultado de una evolución natural, como se puede apreciar analizando la historia del término 'ensayo'. Aunque la palabra existió desde las primeras ediciones del diccionario de la Real Academia Española (RAE), su definición no incluye ninguna referencia al campo literario sino hasta 1869. En su segunda acepción el diccionario indica: "Escrito, generalmente breve, sin el aparato ni la extensión que requiere un tratado completo sobre la misma materia". Es evidente que la definición, más que ser descriptiva e inclusiva resulta negativa. A partir de ella se entiende que se trata de un texto de corta extensión, y luego se sabe lo que no es un ensayo en relación con un tratado. Con el paso del tiempo y el rigor de los 
redactores del diccionario, obviamente, la definición cambió, pero no en su totalidad. La edición de 1992 define ensayo como "Escrito, generalmente breve, constituido por pensamientos del autor sobre un tema, sin el aparato ni la extensión que requiere un tratado completo sobre la misma materia". Que la brevedad sea una característica es un tanto vago, pues para entender criterios de magnitud es necesario contar con un una base comparativa bien definida. Es posible que antes de 1869 los ensayos tuvieran menos palabras que un tratado o una novela, pero ya en 1992 es muy común encontrar volúmenes completos que albergan un solo ensayo, sin ser tratado; entonces la brevedad no constituiría una característica esencial. Junto a la palabra 'ensayo' el tiempo colocó otros dos términos que el diccionario debió incluir: 'ensayista' (1925, "escritor de ensayos") y 'ensayismo' (1936, "género literario constituido por el ensayo"). Para la edición de 1989, la RAE modificó esta última definición: "Actitud del tratadista que deriva hacia lo general o superficial, cuando cabría esperar de él mayores precisiones y una actitud más técnica o comprometida". Naturalmente esta modificación presenta lo 'ensayístico' como una carencia de oficio en el tratadista, incluso desde una perspectiva moral, como si pasar del tratado al ensayo implicara un descenso en la jerarquía intelectual de quien lo lleva a cabo, según el horizonte de expectativas del lector. Estas definiciones son altamente susceptibles de crítica, sobre todo porque aparecieron cuando el término ya había sido adoptado por un número relativamente alto de usuarios y había consolidado un lugar en la historia de la literatura en lengua española. En el siglo XIII nació el soneto en el sur de la Península Itálica. No hubo sonetos antes del soneto y, de ahí en adelante, cualquier texto que pretenda llamarse soneto debe cumplir las características formales establecidas en aquel momento. Con el ensayo no ocurre lo mismo. Antes de la producción literaria de ensayos, como los consideramos ahora, ya había textos similares que no eran llamados ensayos, sino epístolas, discursos e incluso tratados. El término 'ensayo' ya existía antes de su uso en contextos literarios, pero se aplicaba a otros campos del quehacer humano. Es decir, antes del ensayo ya había ensayos, pero no eran textos, sino actividades que no tenían conexión alguna con la literatura en sentido estricto. Como ya se vio, el diccionario lo confirma, el lema se ve en la necesidad de adquirir una nueva significación porque el uso así lo establece.

Cabe precisar que la palabra 'ensayo' sí había sido empleada siglos atrás por varios escritores en el campo literario con dos sentidos fundamentales: 1) aproximación o intento de realizar una obra de mayor empeño y 2) exposición breve, no necesariamente exhaustiva sobre algún tema. Para entender el primer significado, baste citar un texto representativo, el Ensayo de diccionario geográfico-geológico de Juan Vilanova y Piera (Madrid: Imprenta Central, 1884), en cuya introducción se especifica que se trata de un ensayo, es decir, de una obra que pretende la mayor proximidad con un diccionario, pero que no llega a serlo cabalmente. De hecho, presentar la obra como tal permite la legitimidad y necesidad de ulteriores enmiendas. El autor explícitamente "somete al juicio de cuantos se dignen recorrer sus páginas, y anotar en el blanco de éstas así los defectos que de seguro encontrarán, como las omisiones que se habrán cometido" (Villanova, 1884: vii). Que estas anotaciones lleguen a formar parte de la 
edición final del diccionario se mantiene en un plano meramente hipotético. En todo caso, importa subrayar que ya desde el título se marca esta posibilidad: el lector interesado está autorizado para modificar este Ensayo con la esperanza de que "llegará en su día a convertirse en verdadero Diccionario polígloto de voces geográficas y geológicas lo que hoy publica por vía de Ensayo o bosquejo" (Villanova, 1884: vii). Como éste, son numerosos los textos que se publicaron con intenciones similares, justamente marcados con títulos que comienzan por "Ensayo de..." Junto a esta aplicación de la palabra 'ensayo' se puede hacer referencia a otros títulos como Ensayos líricos de Javier Valdelomar y Pineda (Sevilla: José Morales, 1840) o Ensayos poéticos de Fernando de la Vera e Isla Fernández (París: Pillet Fils Ainé, 1852). En estas obras, sin embargo, 'ensayo' tiene una mayor proximidad con la noción de 'ejercicio' literario. De hecho, Valdelomar señala: "Podrán carecer de mérito los ensayos de la juventud, mas no de verdad sus afectos" (Valdelomar, 1840: 6), refiriéndose obviamente a su propia obra juvenil, a sus primeras prácticas literarias. Aquí también, el apelativo 'ensayo' marca un proceso de perfección que, en dado caso, prevendría que la obra fuera ulteriormente criticada bajo los parámetros de un producto cabal ejecutado en plena madurez.

Sobre el segundo significado de la palabra hay varios ejemplos ya desde el siglo XVIII, donde 'ensayo' se utiliza sin el soporte de ninguna definición de diccionario. Por citar algunos ejemplos, Tomás Sebastián y Latre escribe su Ensayo sobre el teatro español (Madrid: P. Marin, 1773) justamente como una exposición general del tema, y Francisco Javier Llampillas, unos años después, publica Ensayo histórico-apologético de la literatura española contra las opiniones preocupadas de algunos escritores modernos italianos (Zaragoza: Blas Miedes, 1782), y también aquí el autor emplea el término 'ensayo' como forma literaria emparentada con el tratado, pero sin pretender los mismos alcances.

Si bien en el siglo XVIII la palabra no contaba con un sustento bibliográfico que respaldara su inclusión en el ámbito hispánico, en otros lugares de Europa el essai francés había sido adoptado para referirse a un determinado tipo de textos. Samuel D. Johnson, en la edición de 1788 de A Dictionary of the English Language (Londres: Knapton and Longman), en la segunda acepción del lema 'essay' indica: "A loose sally of the mind; an irregular indigested piece; not a regular and orderly composition" $\mathrm{y}$ cita a Bacon como autoridad: "My essays, of all my other Works have been most current". El italiano, por su parte, contaba con la palabra assagio o assaggio que tampoco surgió como término literario. Saggio en italiano indica más bien 'espécimen' o 'cala', particularmente en relación con la pequeña muestra de un elemento (por ejemplo, oro) para conocer la autenticidad del resto. Saggio aparece junto a saggiatore que no es 'ensayista', sino 'ensayador', o sea, quien verifica la pureza de un metal precioso. Los diccionarios italianos no modifican las acepciones del término sino hasta el siglo XX, de modo que saggista aparecerá como calco del inglés essayist y se utiliza como sustantivo para designar al escritor de ensayos, a la vez que saggio adquiere una nueva acepción que se agrega a las que ya poseía (sabio, hábil, prueba, cala, demostración): "scritto di carattere critico su un particolare argomento", según el diccionario Garzanti 
en su edición del año 2000. En efecto, la palabra assaggio retuvo algún tipo de influencia en el español antiguo, como lo confirma Sebastián de Covarrubias en el Tesoro de la lengua castellana o española, donde 'ensayar' recibe esta definición: "Vale hazer prueba y díxose del verbo toscano, assaggiare per acuratamente sentire, onde si dize assaggiare il vino. Esto dize Francisco Alumno de Ferrara, en su diccionario llamado Fábrica del mundo. En España usamos deste término en el examen que hazemos del oro y plata y los demás metales y es término muy usado y ay oficio en las casas de la moneda de ensayador".

La difusión de la palabra fuera de España y su empleo en castellano fueron registrados por Rafael María Barlat en su Diccionario de galicismos o sea de las voces, locuciones y frases tomadas de la lengua francesa (Madrid: Imprenta Nacional, 1855). Bajo el lema 'ensayo' escribe:

Aplicado como título a algunas obras, ya por modestia de sus autores, ya porque en ellas no se trata con toda profundidad la materia sobre que versan, ya, en fin, porque son primeras producciones ó escritos de alguna persona que desconfía del acierto, y propone con cautela sus opiniones, es voz de origen italiano (assaggio) y generalmente adoptada por todas las naciones cultas. Su introducción entre nosotros no data de muy antiguo: acaso sea de principios del presente siglo.

Como quiera, esta acepción de ENSAYO no desdice de la que vulgarmente tiene de examen, reconocimiento, prueba; y no hay motivo para desecharla: cuanto más que ya se la puede considerar como consagrada por el uso. Algunos, sin embargo, preferirían que se dijese, en el caso de que tratamos, BosQuEJo, EXAMEN SUCINTO, TRAZO; y tomando metáfora a la pintura, ESQUICIO, ESBOZO, BORRÓN: pero sobre ser muchos de estos vocablos peregrinos, y por lo tanto afectados, ninguno de ellos expresa lo que ENSAYO. El que más se le acerca es BosQUeJo (Barlat, 1855: 244-245).

Como bien señala Todorov, “une notion peut avoir droit à l'existence sans qu'un mot précis du vocabulaire lui corresponde" (Todorov, 1978: 13). Atendiendo la fortuna del término en cuestión, es indudable que primero nacieron los ensayos y luego se les bautizó en español, como ha sido analizado por reconocidos estudiosos de literatura española (Alvar, 1983, y Mainer, 1996). En francés, evidentemente, la historia es muy diferente porque a este nuevo género literario Montaigne le puso un nombre desde el principio: essai. Dando algunos saltos en el tiempo, ya en contexto mexicano, Balbino Dávalos en su Ensayo de crítica literaria (México: La Europea, 1901) analiza algunas traducciones de Horacio hechas por Joaquín D. Casasús. El libro comienza con una descripción de la edición de Casasús, luego reflexiona sobre Horacio y pasa del análisis literario al comentario de las traducciones, sin que esto implique, como dicen las definiciones de la época, un tratamiento profundo del tema; y seguramente el lector de ahora reconocería la escritura de Dávalos como perteneciente al género ensayístico, sin necesidad de recurrir a la historia de la palabra para intentar comprender su significado.

Así, pues, el uso de la palabra 'ensayo' para referirse a textos de carácter crítico —independientemente de su extensión — es bastante reciente, lo cual no implica, na- 
turalmente, que antes de su adopción generalizada los ensayos no hubiesen existido. Hay quienes afirman, incluso, que las características del ensayo contemporáneo se pueden rastrear desde las Noches áticas de Aulo Gelio, e incluso en las epístolas de Séneca y Plutarco, aunque la pertinencia de tal afirmación podría ser muy discutible. Grosso modo Aristóteles se podría considerar el primer ensayista, luego Plutarco, Séneca, Cicerón y Maquiavelo hasta llegar a Montaigne (1580) y Bacon (1597), que inauguran el ensayo moderno (García, 1991, y Gómez, 1996). Es un hecho, sin embargo, que antes de que el ensayo tuviera nombre y abolengo, ya existían otras formas literarias que cumplían la función del ensayo como difusoras de ideas personales o colectivas: tratados, epístolas, anotaciones, discursos, libros de varia lección, diálogos, digresiones, etcétera. Varios de estos géneros, en sentido estricto, son abordados con tanta libertad por los intelectuales del pasado que hoy por hoy resulta a veces complicado encontrar la diferencia entre una anotación, un discurso y el actual ensayo. En realidad la tipología acerca de textos narrativos, expositivos, argumentativos, etcétera, tampoco resulta de gran utilidad porque en un mismo ensayo se pueden encontrar yuxtapuestos varios elementos propios de un determinado género literario sin que esto dé como resultado un texto de caprichosa descodificación o absolutamente ilegible. Miguel Cané titula Ensayos (Buenos Aires: Imprenta de la Tribuna, 1877) su recopilación de artículos periodísticos justamente por tratarse de "ligeros trabajos, destinados casi todos a la vida efímera de un diario. Desde luego, no hay plan ninguno ni ilación entre ellos. Una lectura, una impresión, un recuerdo o una esperanza, he ahí de donde han salido, incompletos, desaliñados, sin soñar jamás en el honor de verse encuadernados" (Cané, 1887: 7). La elección de Cané resulta significativa: ¿por qué llamarle ensayo a un artículo periodístico? Esto deja ver que ya desde el siglo XIX el título de ensayo podía aplicarse a todos aquellos escritos que por su naturaleza textual y su "modernidad" no merecían algún nombre acuñado por la tradición.

El ordo fortuitus que suele acompañar la conceptualización del término 'ensayo' es producto de la soltura con la que el ensayista trata una materia. Sin embargo, cabe hacer una precisión: cuando el ensayista advierte sobre la falta de conexión que hay en sus ensayos, no se refiere a un modo libre y desordenado de exponer las ideas, sino justamente al orden fortuito en que lo hará, es decir, al no tratarse de un texto con pretensiones científicas donde es necesaria la exposición, la prueba y los resultados - como en un tratado-, los temas pueden ser operados desde cualquier ángulo, incluso in medias res, sin que esto implique falta de cohesión ni coherencia en el texto. En las recopilaciones de ensayos la ausencia de conexiones entre los diferentes textos es común, porque el ensayo es una entidad autosuficiente que se puede enriquecer con las demás obras de un mismo autor o de una misma época, pero, por mero principio de lógica discursiva, un ensayo escrito con cierta seriedad cumple generalmente con requisitos básicos de redacción, incluso si su lenguaje se acerca a lo lírico.

Por su carácter persuasivo, el ensayo podría considerarse, sin duda, un auténtico ejercicio retórico. El ensayista, al final de cuentas, es un heredero del antiguo orador grecolatino porque ambos comparten natural y forzosamente la retórica como herra- 
mienta. Detrás de la persuasión se encuentra necesariamente el juicio valorativo, y en este sentido el ensayo es necesariamente también un ejercicio crítico. El ensayista, como cualquier otro usuario de las palabras mediadas por el intelecto, abstrae su pensamiento para después verbalizarlo sobre un andamiaje idealmente lógico. En este proceso de abstracción, el ensayista, como el poeta o el historiador, decide cómo organizar su discurso, qué elementos deben sobresalir y cuáles pueden quedar ocultos, para que el producto final no sólo sea coherente o placentero, sino convincente.

Como género literario, el ensayo padece de juventud y busca identidad sin quedar jamás satisfecho. Antes de él la epístola y el tratado cumplían la función de trasladar el pensamiento crítico en palabras; después de él, el ancla del positivismo o la sana metodología del estudio concienzudo exigieron irremediablemente una clasificación darwiniana en busca de una posible disección de sus componentes. La identidad del ensayo es incierta, vaga, mutable, pero no necesariamente contradictoria en sí misma. Si se ponen en relación las diferentes valoraciones que han sufrido tanto el género ensayístico como el ensayista, se verá que cada época y cada tradición literaria tienen algo diferente que decir a propósito de esta cuestión. La tradición francesa no puede prescindir de Montaigne ni la inglesa de Bacon (Routh, 1920). En el caso de la tradición hispánica, el estudio del ensayo suele analizarse desde la perspectiva europea y latinoamericana casi por separado porque la producción ensayística está fuertemente vinculada con las circunstancias políticas y sociales que, evidentemente, no son las mismas en las dos áreas geográficas.

Para entender algunos problemas literarios que nacieron con el ensayo sería conveniente revisar algunos aspectos de la tradición occidental. Para empezar, no podría faltar Montaigne, el padre del género. Por lo visto, el escritor francés estaba totalmente consciente de lo que hacía, si tenía en mente la diferencia entre informar y argumentar, o sea, si para él la dialéctica y la retórica podían convivir en armonía o si se trataba de dos realidades disociables. En su nota al lector de los Essais aclara lo siguiente: “C'est icy un livre de bonne foy, lecteur. Il t'advertit dès l'entrée, que je ne m'y suis proposé aucune fin, que domestique et privée. Je n'y ay eu nulle consideration de ton service, ny de ma gloire" (Montaigne, 1963: 9). Como ya lo ha notado Liliana Weinberg, es muy significativo que el autor advierta desde el principio que se trata de un libro de buena fe, cuyo contenido es, ante todo, privado y doméstico:

Todo ensayo remite siempre a la perspectiva del sujeto y su capacidad de juicio, y esta remisión al sujeto debe considerarse también como un acto de buena fe, tarea descomunal si se piensa que, en el caso de Montaigne, se trata de oponer este principio al criterio de autoridad y al sistema jerárquico de conocimiento imperante en su época, como permanentemente ha sido el caso del ensayo: su inconformismo, su carácter crítico y su apoyo en la perspectiva sincera del autor (Weinberg, 2001: 15).

Los escritores del Renacimiento solían recurrir a este tipo de frases como parte de su imprescindible captatio benevolentiae, y por eso resultan más atractivos los términos 
que Montaigne emplea para calificar su texto. Si en general la captatio benevolentiae se presenta con exceso de modestia, ¿qué quiso decir Montaigne con "bonne foy" y, sobre todo, por qué aparece la palabra "gloire"? No dudo que el padre del ensayo haya tenido bien claro el alcance de este género entre los lectores, en oposición al tratado, por ejemplo, género prosístico no ficcional por excelencia desde el siglo XIII hasta el XVIII, que incluso él mismo practicó.

En la advertencia al lector, Montaigne caracteriza el ensayo como una forma de comunicar el pensamiento "simple, naturelle et ordinaire, sans contention et artifice" (Montaigne, 1963: 9) y, sobre todo, de manera libre. La libertad es otra característica que suele acompañar las definiciones del ensayo, pero no hay que olvidar que esta palabra ha sufrido muchas modificaciones desde la libertas latina. En estas líneas no era la intención de Montaigne presentar una descripción a priori de su actividad literaria; por eso considero que tal vez sea injusto pedirle respuestas a quien no las tiene, no por deficiencia artística o intelectual, sino por desenfado literario. Montaigne simplemente inauguró el género que, después de todo, nació a partir de una necesidad comunicativa en una época de crisis y relativa emancipación intelectual en Francia. Seguramente él nunca imaginó que la forma y no así el contenido de sus textos, habría de ser tema de agudas disquisiciones literarias para los futuros lectores, aunque de algún modo la intuía. No hay que pretender que el ensayista francés explique con precisión las características de sus textos bajo la mirada del estudioso del siglo XXI. Lo que sí enriquece el estudio es comparar sus ensayos con los homólogos actuales y descubrir que, a pesar de haberse generado bajo circunstancias geográficas y temporales disímiles, hay en la ensayística mundial muchos puntos de contacto con Montaigne, del mismo modo que ocurre con la poesía y las artes en general.

Después de Montaigne, Locke y Leibnitz adoptan el término 'ensayo' para dar nombre a sus reflexiones filosóficas, de modo tal que poco a poco 'ensayo' es sinónimo de reflexión personal, breve, contundente, y no necesariamente inscrita dentro de un sistema de ideas. Con el afortunado devenir de medios escritos de comunicación masiva, el ensayo se mezcla con la nota informativa y afloran escritores de este género en todos los campos del conocimiento. Es justo en el siglo XIX cuando la prensa, la inquietud filosófica-literaria y los acontecimientos históricos dan lugar al ensayo humanístico dentro de periódicos y revistas. Y es justamente aquí cuando México entra en escena con atractivos productos del intelecto humano. En efecto, Arturo Andrés Roig señala que

[...] el escritor romántico y, en particular, el romántico social, no cultivó entre nosotros las letras por sí mismas, hecho que ha sido señal de refinamiento y de decadencia social más de una vez. Se trataba de escritores que se ponían a la tarea cuando tenían algo que decir y sus hábitos se aproximaban más al estilo periodístico de la época, ese al que, como luego veremos, se denominó 'periodismo de ensayo', que a los estilos que se habrían de generar más tarde (Roig, 1986: 128). 
En el continente americano el ensayo se vuelve el género fundamental en las revistas decimonónicas, primero en las de lengua inglesa - durante todo el siglo XIX- y a mitad del siglo, también en las hispanas. Si bien estudiar los orígenes y la evolución del género ensayístico en el siglo Xx puede aportar datos interesantes, el estudioso del ensayo moderno se enfrenta a un problema de género, pues dado que el ensayo nunca estuvo contemplado en las preceptivas literarias que formaron la tradición occidental, no hay ningún tipo de reglas o descripciones acerca de cómo debería elaborarse un texto de esta naturaleza. Llama la atención que hablar del ensayo como género o como procedimiento de escritura no está contemplado en los textos preceptivos o descriptivos elaborados por ensayistas latinoamericanos de principios del siglo XX.

Partiendo del principio de identidad latinoamericana, Medardo Vitier encuentra un reflejo de la realidad continental justamente en sus ensayos, pues es allí donde el pensamiento de América Latina toma formas concretas. De hecho, afirma que "el ensayo aviva, sobre todo de unos cincuenta años acá, las mejores savias del americanismo" (8). Ya en este primer estudio sistemático sobre el ensayo se considera importante no usar el término en sentido amplio. Según Vitier, el ensayo

[...] es una composición en prosa (lo cual no es tan obvio como parece, pues en la literatura inglesa, sobre todo, hay piezas en verso que son y se titulan essays); su naturaleza es interpretativa, pero muy flexible en cuanto a método y estilo; sus temas, variadísimos, los trata el autor desde un punto de vista personal; la extensión, aunque varía, permite por lo común que el escrito se lea de una sola vez; revela, en fin, las modalidades subjetivas del escritor (Vitier, 1945: 46).

Vitier nota en el ensayo americano una especie de género híbrido, pues a la vez que se caracteriza por cierto rigor en su desarrollo, como todo texto didáctico, hay siempre en él un tono poético y una absoluta libertad ideológica. Formalmente el ensayo debe distinguirse del tratado o la monografía, donde el reflejo de la individualidad del escritor no es un rasgo característico, y también del artículo periodístico, según Vitier, aunque esto último es más complicado debido al gran número de particularidades compartidas entre estos dos géneros. Vitier hace una clasificación tentativa de los diversos tipos de ensayo tomando en cuenta criterios de estilo, longitud y relevancia del tema tratado - elementos que no son objetivamente mesurables. Así, existe un ENSAYO DE ERUDICIÓN, que sería sinónimo de monografía; un ENSAYO DE FILIACIÓN, que "fomenta los vínculos latinoamericanos" (Vitier, 1945: 9), y un ENSAYO DE PROBLEMAS, donde se tratan temas comunes en varias realidades nacionales. Esta clasificación, sin embargo, resulta demasiado restrictiva porque deja fuera muchos textos que se apartan de la reflexión nacionalista. Como respuesta a estas deficiencias, José Luis Martínez en El ensayo mexicano moderno (1958) subraya, sobre todo, el carácter parcial e individualista del texto, así como su naturaleza interpretativa. El ensayo se distingue de otros géneros por la originalidad en el modo de escribir, la variedad de formas de pensar y la sistematización de ideas; en consecuencia, flexibilidad, subjetividad y 
libertad formal e ideológica son elementos esenciales del género. El autor considera oportuno presentar de manera esquemática las distintas modalidades del ensayo que, a pesar de ser discutibles, sientan las bases para una taxonomía que tome en cuenta las orientaciones del ensayo hacia el texto de creación literaria, el discurso, la crónica, el artículo periodístico, etcétera. Sin embargo, los límites del ensayo son tan indeterminados que cualquier clasificación carece de los infinitos matices que se encuentran en la raíz y en la naturaleza propia del texto. Un ensayo de creación literaria no es necesariamente opuesto a uno informativo, así como un artículo periodístico no tiene por qué diferir en todo de un ensayo de pretensiones edificantes. Quede claro que éstas son observaciones a partir del estudio de ensayos existentes, no intentos de descripción con trasfondo preceptivo.

Martínez anota con precisión que es en los ensayos mexicanos donde se encuentran concentrados no sólo el pensamiento, sino la historia de la cultura y de los problemas de la nación: en el ensayo rara vez la inteligencia y la sensibilidad actúan en favor del simple goce intelectual o estético. En general, los escritores se ponen al servicio de la cultura en sus diversas manifestaciones: literatura, arte, filosofía, antropología, historia, economía, etcétera. Señala el autor que el principal ejercicio literario de los ensayistas mexicanos no es precisamente éste: son numerosos los abogados, filósofos, médicos y, obviamente, poetas, los que se dedicaron a la escritura de ensayos y artículos periodísticos de diversa índole como parte de sus intereses culturales o como actividad económicamente redituable. Martínez comenta que "un movimiento literario se reconoce sobre todo por sus nuevas características de estilo; pero como en el ensayo la función del estilo es menos importante que la corriente ideológica, sus características sólo excepcionalmente permiten distinguir con claridad una verdadera escuela literaria" (Martínez, 1958: 20). En el caso de los ensayistas mexicanos, este razonamiento se aplica bastante bien, pues difícilmente se podría encontrar homogeneidad en los puntos de vista de sus miembros, aunque la mayoría haya tratado temas similares.

En la actualidad, la indefinición del ensayo sigue abriendo las puertas a múltiples acercamientos teóricos y analíticos. Se nota, sin embargo, un interés por partir de las generalidades marcadas por la historia de la literatura para llegar a la exposición de fenómenos determinados que se observan en cada tradición literaria, ya sea por afinidades lingüísticas, cronológicas, regionales, o nacionales. Esto se debe, en gran medida, a las particularidades específicas del pensamiento y su expresión a lo largo de la historia misma; de modo que podemos encontrar estudios sobre el ensayo latinoamericano, el ensayo mexicano, el ensayo mexicano del siglo XIX, el ensayo mexicano de crítica de arte del siglo XIX, el ensayo mexicano de crítica de arte en la prensa del siglo XIX, y así, hasta llegar a precisiones más específicas que puedan limitar los campos de estudio según intereses particulares (tipo de medios, características identitarias de los autores, contenidos, ideologías, momentos históricos, etcétera), con la finalidad de interpretar con detalle las causas y consecuencias de ciertos procesos de creación en un tiempo y lugar determinados. 


\section{$248 \square$ ENSAYANDO UNA REFLEXIÓN SOBRE EL ENSAYO}

El día de hoy, dentro del ámbito hispánico, contamos con una muy rica bibliografía sobre el estudio del ensayo como género literario. Según mi experiencia docente, Teoría del ensayo de José Luis Gómez-Martínez (2a. ed. México, UnAM, 1992) sigue manteniendo vigencia por su carácter general y sintético. Dejando a un lado varias de las preocupaciones para definir el género - que no por ser del pasado dejan de ser importantes - el autor divide su texto en dos partes. En la primera, ofrece información general sobre el término 'ensayo' en sentido lingüístico y de ahí salta a sus características y condicionantes esenciales, sin ser exhaustivo, pero indicando con claridad los puntos problemáticos de mayor relevancia para un estudio pormenorizado. En la segunda parte, elabora una antología de breves reflexiones sobre el ensayo generadas en ámbito hispanoamericano desde 1924 hasta 1987. Además, el estudio tiene como virtud un aparato bibliográfico de gran utilidad. Después de este libro, quien quiera profundizar en la materia está obligado a acercarse a tres textos de carácter reflexivo escritos por Liliana Weinberg: El ensayo, entre el paraíso y el infierno (México, UNAM / FCE, 2001), Umbrales del ensayo (México, unAm, 2004) y Situación del ensayo (México, UNAM, 2006). Productos de una meditación constante, estas tres obras abren panoramas de análisis sobre el ensayo que - aunque suelen partir de una base latinoamericanafácilmente pueden aplicarse a realidades ensayísticas producidas en cualquier contexto lingüístico.

Si el ensayo es la materialización de un pensamiento, resulta obvio que su estudio es indispensable para entender la historia de las ideas que han ido modificando el mundo moderno. En este sentido, me parece altamente proficuo reflexionar de vez en cuando acerca de los alcances del género desde su perspectiva histórica, ideológica y literaria. Mucho se ha dicho sobre el ensayo, es cierto: al basarse en el pensamiento humano la reflexión será siempre infinita.

\section{Obras citadas}

Todas las referencias a libros decimonónicos o anteriores provienen de ediciones digitales: www.archive.org

Alvar, Manuel.1983. "La turbada historia de la palabra Ensayo". Dispositio, 2223. Pp. 145-168.

BARLAT, Rafael María. 1855. Diccionario de galicismos o sea de las voces, locuciones y frases tomadas de la lengua francesa. Madrid: Imprenta Nacional.

CANÉ, Miguel. 1877. Ensayos. Buenos Aires: Imprenta de la Tribuna.

Covarrubias, Sebastián de. 2003. Tesoro de la lengua castellana o española. Ed.

Martín DE RIQUER. Barcelona: Alta Fulla. (Ad Litteram, 3)

DÁvalos, Balbino. 1901. Ensayo de crítica literaria. México: La Europea.

García GuAL, Carlos. 1991. "Ensayando el 'ensayo': Plutarco como precursor”. Revista de Occidente, 116. Pp. 25-43. 
GómEZ, Jesús, ed. 1996. El ensayo español, vol. 1, Los orígenes: siglos XV a XVII. Barcelona: Crítica.

Gómez-MARTínez, José Luis. 1922. Teoría del ensayo. México: UnAM.

Il grande dizionario Garzanti della lingua italiana. 2000. Milán: Garzanti.

JoHnson, Samuel D. 1788. Dictionary of the English Language. Londres: Knapton and Longman.

LAMPILLAS, Francisco Javier. 1782. Ensayo histórico-apologético de la literatura española contra las opiniones preocupadas de algunos escritores modernos italianos. Zaragoza: Blas Miedes.

MAINER, José-Carlos. 1996. "Apuntes junto al ensayo". Ed. Jesús Gómez. El ensayo español, vol. 1, Los orígenes: siglos XV a XVII. Barcelona: Crítica. Pp. 9-33.

María BARLat, Rafael. 1855. Diccionario de galicismos o sea de las voces, locuciones y frases tomadas de la lengua francesa. Madrid: Imprenta Nacional.

MARTíneZ, José Luis. 1958. El ensayo mexicano moderno. México: FCE.

Montaigne, Michel de. 1963. Essais, Euvres complètes. París: Gallimard.

RoIG, Arturo Andrés. 1986. "El siglo XIX latinoamericano y las nuevas formas discursivas". El pensamiento latinoamericano en el siglo XIX. Quito / México: Instituto Panamericano de Geografía e Historia. Pp. 127-140.

Routh, H. V. 1920. "The origins of the essay compared in French and English literatures". Modern Language Review, XV. Pp. 28-41.

SEbastián y Latre, Tomás. 1773. Ensayo sobre el teatro español. Madrid: P. Marin.

Todorov, Tzvetan. 1978. Les genres du discours. París: Seuil.

VAldelomar y PINEDA, Javier. 1840. Ensayos líricos. Sevilla: José Morales.

Vera e Isla Fernández, Fernando de la. 1852. Ensayos poéticos. París: Pillet Fils Ainé.

VITIER, Medardo. 1945. Del ensayo americano. México: FCE.

WeInBERg, Liliana. 2006. Situación del ensayo. México: UnAM. 2004. Umbrales del ensayo. México: UNAM. 2001. El ensayo, entre el paraiso y el infierno. México: UNAM / FCE. 